\title{
HIGHER ORDER CORRECTED TRAPEZOIDAL RULES IN LEBESGUE AND ALEXIEWICZ SPACES
}

\author{
ERIK TALVILA
}

Abstract. If $f:[a, b] \rightarrow \mathbb{R}$ such that $f^{(n)}$ is integrable then integration by parts gives the formula

$$
\int_{a}^{b} f(x) d x=\frac{(-1)^{n}}{n !} \sum_{k=0}^{n-1}(-1)^{n-k-1}\left[\phi_{n}^{(n-k-1)}(a) f^{(k)}(a)-\phi_{n}^{(n-k-1)}(b) f^{(k)}(b)\right]+E_{n}(f),
$$

where $\phi_{n}$ is a monic polynomial of degree $n$ and the error is given by

$$
E_{n}(f)=\frac{(-1)^{n}}{n !} \int_{a}^{b} f^{(n)}(x) \phi_{n}(x) d x .
$$

This then gives a quadrature formula for $\int_{a}^{b} f(x) d x$. The polynomial $\phi_{n}$ is chosen to optimize the error estimate under the assumption that $f^{(n)} \in L^{p}([a, b])$ for some $1 \leqslant p \leqslant \infty$ or if $f^{(n)}$ is integrable in the distributional or Henstock-Kurzweil sense. Sharp error estimates are obtained. It is shown that this formula is exact for all such $\phi_{n}$ if $f$ is a polynomial of degree at most $n-1$. If $\phi_{n}$ is a Legendre polynomial then the formula is exact for $f$ a polynomial of degree at most $2 n-1$.

Mathematics subject classification (2010): Primary 26D15, 41A55, 65D30; Secondary 26A39, 46F10. Keywords and phrases: Numerical integration, quadrature, corrected trapezoidal rule, Lebesgue space, Henstock-Kurzweil integral, Alexiewicz norm, continuous primitive integral.

\section{REFERENCES}

[1] M. Abramowitz And I. A. Stegun, Handbook of mathematical functions, New York, Dover, 1965.

[2] P. Cerone And S. S. Dragomir, Trapezoidal-type rules from an inequalities point of view, in: G. Anastassiou (Ed.), Handbook of analytic-computational methods in applied mathematics, New York, CRC Press, 2000, pp. 65-134.

[3] E. W. ChEneY, Introduction to approximation theory, New York, Chelsea, 1982.

[4] D. Cruz-Uribe And C. J. Neugebauer, Sharp error bounds for the trapezoidal rule and Simpson's rule, JIPAM. J. Inequal. Pure Appl. Math. 3 (2002), Article 49, 22 pp.

[5] P. J. DAVIS, Interpolation and approximation, New York, Dover, 1975.

[6] Lu. Dedić, M. Matić And J. PečArić, On Euler trapezoid formulae, Appl. Math. Comput. 123 (2001), 37-62.

[7] R. A. DeVore and G. G. Lorentz, Constructive approximation, Berlin, Springer-Verlag, 1993.

[8] X. Ding, G. YE, W.-C. YANG, Estimates of the integral remainders in several numerical integral formulas using the Henstock-Kurzweil integral, J. Math. Inequal. 3 (2009), 243-256.

[9] F. Dubeau, On corrected quadrature rules and optimal error bounds, Abstr. Appl. Anal. 2015 (2015), 461918, 9 pp.

[10] J. Gillis AND G. Lewis, Monic polynomials with minimal norm, J. Approx. Theory 34 (1982), 187-193.

[11] M. Golomb, Lectures on theory of approximation, Argonne National Laboratory, Applied Mathematics Division, 1962. 
[12] I. S. GRAdShTEYN AND I. M. RYZHIK, Table of integrals, series, and products (trans. Scripta Technica, Inc., ed. A. Jeffrey and D. Zwillinger), San Diego, Academic Press, 2007.

[13] V. I. KRYLov, Approximate calculation of integrals (trans. A. H. Stroud), New York, Dover, 2005.

[14] P.-Y. LEE, Lanzhou lectures on Henstock integration, Singapore, World Scientific, 1989.

[15] E. H. Lieb ANd M. Loss, Analysis, Providence, American Mathematical Society, 2001.

[16] Z. Liu, Error estimates for some composite corrected quadrature rules, Appl. Math. Lett. 22 (2009), $771-775$.

[17] G. G. Lorentz, Approximation of functions, New York, Holt, Rinehart and Winston, 1966.

[18] I. P. NAtanson, Constructive function theory, Vol. I, (A. N. Obolensky, trans.), New York, Frederick Ungar, 1964.

[19] I. P. Natanson, Constructive function theory, Vol. II, (J. R. Schulenberger, trans.), New York, Frederick Ungar, 1965.

[20] J. PeČARIĆ AND N. Ujević, A representation of the Peano kernel for some quadrature rules and applications, Proc. R. Soc. Lond. Ser. A Math. Phys. Eng. Sci. 462 (2006), 2817-2832.

[21] T. J. Rivlin, An introduction to the approximation of functions, New York, Dover, 1981.

[22] K.-G. STEFFEns, The History of Approximation Theory, Boston, Birkhäuser, 2006.

[23] C. SwARTZ, Introduction to gauge integrals, Singapore, World Scientific, 2001.

[24] E. Talvila, The distributional Denjoy integral, Real Anal. Exchange 33 (2008), 51-82, 5 (2012), $47-59$.

[25] E. Talvila And M. Wiersma, Optimal error estimates for corrected trapezoidal rules, J. Math. Inequal. 6 (2012), 431-445.

[26] A. F. TIMAn, Theory of approximation of functions of a real variable, (J. Berry, trans., J. Cossar, Ed.), Oxford, Pergamon, 1963. 